\title{
Sentidos de saúde, cuidado e risco para adolescentes residentes na favela da Maré, no Rio de Janeiro, Brasil
}

Marcia Rodrigues Lisboa(a)

Katia Lerner ${ }^{(b)}$

Lisboa MR, Lerner K. Health, care and risk: what do they mean to adolescents living in the Mare favela, Rio de Janeiro, Brazil. Interface (Botucatu). 2017; 21(63):893-906.

This is a qualitative study about the meanings of health, care and risk to Brazilian adolescents living in the Maré favela, in Rio de Janeiro. The analysis is oriented by reflections on the epidemiological perspective that classifies this age group as a risk group, and the media impacts on social relations, through the increase of the circulation of information on the subject. The research had as source the group discussions with adolescents aged between 14 and 16 years old. The study showed competing discourses regarding the risk culture, family traditions and the context of violence in everyday life of the participants. The study highlights the mediation of mothers, physicians working in primary care and the media on the social construction of these meanings.

Keywords: Adolescence. Communication. Health. Care. Risk.
Trata-se de um estudo qualitativo acerca dos sentidos atribuídos aos termos saúde, cuidado e risco por adolescentes brasileiros residentes no conjunto de favelas da Maré, no município do Rio de Janeiro. A análise referencia-se em reflexões sobre a perspectiva epidemiológica de enquadramento dos indivíduos dessa faixa etária na categoria grupo de risco e o processo de midiatização social, que potencializa a circulação de informações a respeito da temática. $O$ principal instrumento de coleta de dados foram discussões em grupo com adolescentes entre 14 e 16 anos. As dinâmicas permitiram observar a presença de discursos concorrentes da cultura do risco, de tradições familiares e do contexto de violência no cotidiano dos participantes. Destacam-se as mediações das mães, dos médicos que atuam na atenção básica e dos meios de comunicação na construção social desses sentidos.

Palavras-chave: Adolescência.

Comunicação. Saúde. Cuidado. Risco.

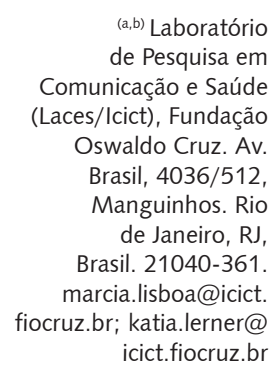

(a,b) Laboratório de Pesquisa em Comunicação e Saúde (Laces/Icict), Fundação Oswaldo Cruz. Av. Brasil, 4036/512, Manguinhos. Rio de Janeiro, RJ

Brasil. 21040-361. marcia.lisboa@icict. fiocruz.br; katia.lerner@ icict.fiocruz.br 


\section{Introdução}

Os cuidados com a saúde vêm constituindo uma preocupação recorrente que se manifesta tanto no nível individual, nas práticas cotidianas dos sujeitos em relação ao seu próprio corpo, quanto em espaços coletivos, por meio da formulação de políticas públicas sobre o tema e de sua crescente visibilidade nos meios de comunicação. No entanto, a ideia de que o corpo e a saúde estão em risco e precisam ser protegidos pela ação humana não se apresenta de forma homogênea entre os distintos grupos sociais. Os contextos diversos trazem dinamismo aos sentidos que essas noções podem adquirir.

Considerando tais questões, este artigo busca compreender os sentidos atribuídos por adolescentes residentes no Conjunto de Favelas da Maré, na cidade do Rio de Janeiro, às noções de saúde, cuidado e risco. A reflexão proposta origina-se de uma pesquisa qualitativa mais ampla, na interface da comunicação com a saúde acerca das formas de apropriação por esses adolescentes de produtos jornalísticos sobre cuidado e risco à saúde ${ }^{1}$.

A análise ilumina, inicialmente, o forte vínculo entre a noção de cuidado com a saúde e o conceito epidemiológico de risco, que vem sendo estabelecido desde meados do século $X X^{2}$. A partir da segunda metade da década de 1980 a ideia de risco à saúde assumiu maior complexidade, quando se tornou central na vida cotidiana, resultante de imbricações múltiplas de diferentes áreas do conhecimento.

Neste cenário, que tem sido gerador de ações e embates no campo da promoção de saúde, a condição de adolescente adquire dimensões particulares por seu enquadramento na categoria grupo de risco. Um primeiro limite dessa perspectiva decorre da redução da adolescência a processos biológicos desencadeadores de padrões de conduta para qualquer pessoa nesse período da vida. Ao naturalizar a adolescência, abdicando do caráter instável do conceito como constructo social, forjam-se a criação de rótulos sobre o ser adolescente e a construção de uma tipologia frequentemente associada à ideia de geração $0^{3,4}$.

A classificação dos adolescentes como grupo de risco é gestada em um ambiente de fobia ao risco que fundamenta ações calcadas no "hiperpreventivismo"5. Os apelos à prevenção de riscos à saúde desse segmento populacional apoiam-se em dados estatísticos epidemiológicos e na disseminação de formulações produzidas por especialistas de áreas médicas e afins - psiquiatria, neurociência, nutrição, entre outras - fomentando argumentos para a deflagração de dispositivos de vigilância.

Uma das diretrizes da saúde pública nesta direção tem sido o estudo de comportamentos de risco dos adolescentes (ou da possibilidade de ocorrerem), seu monitoramento e a consequente intervenção. A investigação na qual se sustenta este artigo buscou fugir de rótulos comportamentais, tendo seguido o percurso de escuta dos adolescentes, por meio da interação em grupo, para observar os processos de construção de sentidos dos temas.

O estudo orienta-se por reflexões teóricas que consideram esses indivíduos inseridos em um contexto de expansão e aprofundamento do modelo capitalista de produção, após a década de 1990. Especialmente relevante à pesquisa é a característica do novo capitalismo de reforçar a associação de atributos considerados típicos dos jovens contemporâneos à dinâmica do mercado de trabalho. Conforme analisam Boltanski e Chiapello ${ }^{6}$, uma das mudanças significativas quanto à antiga organização do trabalho é que o novo mercado aciona dispositivos de autocontrole, envolvimento pessoal e motivação a fim de obter adesão dos indivíduos sem necessidade de comando.

Associada a esta, outra importante modificação despontada na última década do século XX refere-se à apologia da mudança, do risco e da mobilidade, que se contrapõe à ideia de garantia e estabilidade presentes anteriormente. A valorização de atitudes como ousadia, desafio à estabilidade e o inconformismo destaca-se nesse contexto, não mais voltadas a projetos de transformação social, e sim a processos de individuação, direcionados, sobretudo, aos jovens, considerados 'cidadãos do futuro'. Em um contexto no qual a juventude é a norma, evidencia-se "um indivíduo heroico que assume riscos, em vez de buscar proteger-se deles por meio das instituições do Estado-providência"7 (p. 25).

A lógica contraditória que atribui valor ao risco e, ao mesmo tempo, responsabiliza os indivíduos pelas consequências desse mesmo risco ao qual se submetem é potencializada pelo processo de midiatização da sociedade, definido por Sodréé,9 como uma forma exacerbada de mediação das 
tecnologias de informação e comunicação que perpassa as relações sociais. A midiatização ultrapassa os meios tradicionais de comunicação, ganhando projeção nos espaços virtuais de comunicação de múltiplos emissores.

Particularmente provocativa para a pesquisa foi a reflexão sobre esse duplo traço da contemporaneidade - a cultura do risco e a midiatização social - no cotidiano de adolescentes de classes populares que convivem com situações discriminatórias pelo fato de residirem em uma favela, agravadas quando se trata de populações jovens ${ }^{10}$. O estudo considerou os participantes como sujeitos políticos em um território de múltiplas mediações, no qual diferentes atores sociais concorrem na disputa de sentidos.

\section{Metodologia}

A pesquisa mais ampla combinou técnicas de observação direta e indireta: discussões em grupo, descrição densa dos contextos do campo de investigação, aplicação de questionário e produção de diagramas pelos participantes dos grupos. Para atender ao objetivo deste texto, qual seja, identificar os sentidos atribuídos, pelos adolescentes participantes do estudo, às noções de saúde, cuidado e risco, foram privilegiados os resultados obtidos no trabalho em grupo inspirado no instrumento de grupos de discussão.

Trata-se de uma técnica que busca observar os processos interativos e discursivos dos sujeitos de pesquisa. Seguindo esta linha, o pesquisador não conduz a dinâmica, mas propõe um tema como ponto de partida, estimulando o diálogo entre os participantes, que podem fazer associações com outros assuntos, não previstos, redirecionando o debate ${ }^{11}$. A interlocução entre os sujeitos da pesquisa, por meio desta técnica, permite o afloramento dos sentidos circulantes sobre as noções de saúde, cuidado e risco para eles.

As atividades ocorreram entre novembro de 2012 e junho de 2013, com três grupos de adolescentes, de 14 a 16 anos, sendo um deles composto por estudantes de uma escola pública municipal e os outros por participantes de projetos de duas organizações sociais. O primeiro grupo teve seis encontros e os demais, cinco. Quase todos os integrantes eram alunos do $9^{\circ}$ ano do Ensino Fundamental. Apenas três cursavam séries anteriores.

A entrada em campo condicionou-se à autorização das instâncias gestoras das instituições (incluindo as secretarias de Educação e de Saúde do Município do Rio de Janeiro) e ao consentimento esclarecido dos adolescentes e de seus responsáveis. A investigação foi aprovada pelo Comitê de Ética em Pesquisa da Escola Politécnica da Fundação Oswaldo Cruz, sob o parecer número 140.113.

Participaram da pesquisa 33 adolescentes, somados os três grupos. Os encontros tiveram, em média, nove integrantes, e duração em torno de noventa minutos. Tendo em vista que o caráter voluntário da participação foi uma condição inquestionável, explícita no Termo de Consentimento Livre e Esclarecido apresentado a todos (as) por ocasião do convite, considerou-se a evasão inferior às expectativas. A qualquer momento, o (a) adolescente poderia retirar seu consentimento e deixar de participar.

Os dados analisados neste artigo foram coletados, primordialmente, no encontro que abordou a percepção dos adolescentes sobre saúde, cuidado e risco e o papel dos interlocutores que compõem suas redes discursivas na construção desses conceitos. A dinâmica teve início com a solicitação de que fizessem associações livres ao termo 'saúde'. O diálogo continuou com perguntas sobre o que seria uma questão de saúde para os participantes e se pensavam no assunto em algum momento. Em seguida, o disparador foi o termo 'cuidado'. Após fazerem as associações livres acerca dos sentidos da palavra, os adolescentes foram questionados sobre seus interlocutores a respeito do tema. $\mathrm{O}$ termo 'risco' deu continuidade às discussões em grupo.

\section{Da ausência de doença ao bem-estar físico e mental}

A pesquisa tomou como pressuposto a não obviedade da correlação entre saúde, cuidado e risco para os adolescentes. As reflexões foram ancoradas em dois marcos: a passagem do grande modelo 
explicativo da vida, a religião, orientador das representações e práticas sobre a saúde, para o nascimento da medicina moderna, quando o saber médico assumiu a responsabilidade pelo gerenciamento dos $\operatorname{corpos}^{12}$; e a aproximação da saúde ao conceito de risco, fortalecendo a crença no poder da ação humana na antecipação da doença e na possibilidade de controle do adoecimento 2,13.

O entendimento da medicina como política aplicada ao campo da saúde individual, e da política como a aplicação da medicina no âmbito social, a fim de curar "os males da sociedade"14 (p. 302), estava na base do surgimento da medicina social ${ }^{14}$, no contexto da Revolução Industrial, com a incorporação de reivindicações relativas à saúde pelas classes trabalhadoras - especialmente em países como Inglaterra, França e Alemanha - e o posicionamento de médicos e filósofos em direção ao caráter social da medicina e da doença.

No cenário de pós-guerra, a Organização Mundial de Saúde (OMS) definiu, em 1946, a saúde como "o estado de completo bem-estar físico, mental e social, e não meramente a ausência de doença ou incapacidade"15(c) (p. 1).

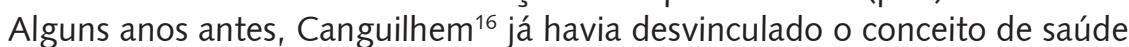
à existência de patologia, em sua tese de doutorado em medicina, que se tornou um marco da epistemologia da saúde. Doença deixava de ter o caráter de desaparecimento de uma ordem fisiológica para ser considerada o aparecimento de uma nova ordem vital; e saúde seria a "margem de tolerância às infidelidades do meio"16 (p. 78).

As intervenções iniciais feitas em um dos grupos da pesquisa revelaram a proximidade entre as maneiras como os adolescentes definiram 'saúde' e o conceito adotado pela OMS em $1946^{15}$. As falas a seguir resultam da proposta de dinâmica na qual eles expressariam o que viesse à cabeça quando ouviam a palavra saúde. A fim de evitar possíveis constrangimentos aos participantes, optou-se por usar nomes fictícios.

\footnotetext{
"Bem-estar físico e mental". (Mariana)

"Cuidado. Equilíbrio entre o físico e o mental". (Guilherme)
}

"O cuidado que a gente tem com essas coisas que o [nome do colega] falou". (Vitor)

"Às vezes a gente se preocupa muito com a saúde física, e esquece um pouco a saúde mental, cuida de um lado e acaba adoecendo do outro". (Guilherme)

“Eu penso primeiramente no médico [risos]. Saúde mental também faz parte, e a gente não pensa muito nisso". (Alex)

No diálogo, observa-se a presença da ideia de saúde vinculada a equilíbrio - que remonta à mais antiga teoria naturalista sobre sofrimento, vida e morte, atribuída a Hipócrates ${ }^{17}$ - e sua associação imediata ao cuidado. Esta visão, no entanto, convive com a que vincula a saúde à figura do médico, segundo expressa Alex, mesmo ponderando não ser este um tema no qual pensasse com frequência. A nomeação do médico informa, ainda, sobre o estatuto deste profissional, seja por meio de histórias pessoais ou de representações sociais.

Também se destaca, nas vozes dos participantes, o enfoque em relação à saúde mental, tema que voltou à pauta em momentos posteriores das discussões em grupo, com as associações feitas às condições de vida no ambiente em que estão inseridos. (c) Health is a state of complete physical, mental and social well-being and not merely the absence of disease or infirmity. 


\footnotetext{
"Acho que chega uma certa etapa da nossa vida, como se tivesse, sei lá, 50 anos hoje, que a gente começa a pensar nisto [em saúde]. Talvez pelo que as pessoas ao nosso redor estejam passando ou uma preocupação brutal, como a que a gente falou na semana passada. [...]". (Guilherme)

“É, também quando acontece algum problema com alguém próximo assim, a gente fica mais ligada nas coisas". (Verônica)

"E também pelos meios de comunicação que a gente tem". (Guilherme)
}

As falas remetem não a situações vivenciadas por eles mesmos, mas por pessoas próximas. Essa referência aparece na intervenção de outro participante do grupo, que vinculou o tema saúde ao "trabalho desgastante" e ao "esforço excessivo, trabalhar demais" (Vitor). Como exemplo, citou os pais.
"Sobre o esforço físico, trabalhar demais mexe com as duas coisas: saúde física e mental. A mental, por exemplo, você trabalha o dia inteiro e só vê a família na parte da noite ou quando chega; e física também, por exemplo, se fica muito tempo parado em frente a um computador, no escritório, pode causar sedentarismo, e esforço físico mesmo no trabalho pode gerar uma lesão". (Vitor)

Destacam-se, em sua fala, a familiaridade com expressões do vocabulário médico, como "sedentarismo" e "lesão", além de elementos de construção semântica de discursos preventivos. Quando perguntado sobre como se informava sobre esses temas, ele atribuiu ao acompanhamento médico: "Desde cedo. A gente frequenta médico toda hora e eles sempre dão informações para a gente".

Em outro grupo (2), a correlação entre saúde, bem-estar e cuidado apareceu igualmente.

\footnotetext{
"[Saúde é] Se sentir bem todos os dias". (Daniel)

"[Ter] Cuidados consigo mesmo". (Paula)
}

Tanto neste grupo quanto no grupo 3 a saúde foi definida como um valor em si, altamente desejável, que remete a um conceito idealista.

\footnotetext{
"Saúde é uma coisa importante. Em primeiro lugar é a saúde". (Carol)

"Para as pessoas continuarem vivas. Se não tiver saúde, você também não tem vida. Vai estar debaixo de um caixão". (Stefany)
}

A clássica oposição saúde-doença apresentou-se nos três grupos, aproximada do binômio vidamorte e da noção de saúde como ausência de doença. Este é, de acordo com Almeida Filho ${ }^{17}$, um dos desafios para a saúde coletiva na contemporaneidade: transformar essa visão em uma concepção positiva de saúde.

Ao serem questionados se pensavam em saúde em algum momento, foi recorrente a expressão: "Quando estou doente". Como variante desta frase, uma adolescente citou a expectativa de ficar doente como algo que a faz pensar em saúde e expressou sua atitude diante da situação: "Aí, eu penso: 'Não vou ficar doente'" (Paula). Percebe-se, no conjunto das frases, a presença de elementos concorrentes à ideia de antecipar-se ao dano, característica dos discursos sobre o risco, associada à lógica ambivalente do risco: "pensar positivamente" e "ser otimista" são algumas recomendações frequentes para a "boa saúde". 
O tema da saúde no contexto das experiências pessoais de doenças foi abordado em um dos grupos:

\author{
"Eu não me dou bem com saúde, ficar doente, essas coisas. Não fico doente direito assim...". \\ (Lucas) \\ "Ah, direto, eu fico doente o tempo todo". (Stefany)
}

No vínculo entre saúde e doença feito por Lucas, as duas palavras não estão em oposição, mas lado a lado, como uma única unidade discursiva. As falas dos dois adolescentes destacam, ainda, a relevância dada à frequência com que ficam doentes ("não fico doente direto" / "fico doente o tempo todo"), seja pela afirmação ou pela negação.

Observa-se a correlação entre comportamentos e danos à saúde, mesmo que não tenham a prática que os exporia a tais danos, como relata Stefany: "Tipo câncer não é uma coisa que você pega numa relação, mas HIV é. Mas como não faço relação nenhuma, só fico no beijo, não tenho medo de pegar. O câncer você pega naturalmente".

Embora dois integrantes deste grupo tenham informado não pensarem em saúde, registrou-se uma preocupação com o tema, com elementos da cultura 'riscofóbica'. Ainda que sejam menos sujeitos ao adoecimento do que adultos, estão inseridos em um contexto comunicativo marcado pela profusão de informações sobre a importância de cuidar do corpo. Não por acaso o risco direto ao próprio corpo, que mais apareceu nas falas, é aquele associado, frequentemente, ao comportamento de adolescentes e jovens, seja na mídia, na escola ou em outros espaços de circulação de informações: a contaminação pelo vírus HIV.

\title{
Alimentação saudável, camisinha e exercício físico
}

A abordagem sobre os sentidos de cuidado para os participantes da pesquisa trouxe componentes ricos para o entendimento de seus processos de apropriação do tema. Se a vinculação entre saúde e cuidado, a partir da apresentação do termo 'saúde', foi imediata, ela não se reproduziu quando a palavra 'cuidado' tornou-se o objeto de discussão. Ou seja: quando os adolescentes fizeram associações livres acerca da palavra 'saúde', o termo 'cuidado' apareceu imediatamente, em todos os grupos, conforme apontado no item anterior; mas quando foram demandados a fazer associações livres com a palavra 'cuidado', não verbalizaram o termo 'saúde'. No entanto, os participantes estabeleceram aproximações entre o termo 'cuidado' e elementos do campo discursivo da saúde, como 'prevenção' e 'alimentação', como se pode verificar adiante.

Este dado foi observado à luz da análise foucaultiana, segundo a qual o princípio de que é preciso ter cuidados consigo estaria na base da existência, fundamentando a sua necessidade, comandando seu desenvolvimento e organizando sua prática ${ }^{18}$. Na abordagem com os adolescentes sobre o cuidado, um termo que surgiu espontaneamente, logo no início dos debates, foi o substantivo 'prevenção' e sua forma verbal 'prevenir', o que aponta não apenas o acesso a informações com este objetivo, como formas de apropriação desses conteúdos, conforme revela o comentário: "É muito aquela coisa que se falou: a gente só tem cuidado quando está doente. [risos] Não tem 'a' prevenção" (Guilherme). O adolescente sinalizou as aspas com o gesto manual, reforçando o artigo, da mesma forma que havia feito anteriormente em referência à saúde. Outros participantes concordaram.

Embora o cuidado tenha sido associado à situação de doença, tal qual ocorreu quando o tema em discussão era a saúde, o registro acerca da prevenção sinaliza a forte presença de discursos nessa perspectiva no cotidiano dos adolescentes pesquisados. Um dos assuntos vinculados por vários participantes, nos três grupos, ao cuidado à saúde foram as práticas alimentares. No grupo 1 , o debate partiu da manifestação de um adolescente sobre a preocupação com a "alimentação em excesso". A referência ao vocábulo "besteira" sinalizou a autocrítica dos adolescentes em relação a seus hábitos, que incorpora o discurso da promoção de saúde associada à boa alimentação. As falas apontam para a apropriação de discursos circulantes sobre a "alimentação saudável". Mesmo quando revelam práticas que contradizem as recomendações, elas são tomadas como referência. 


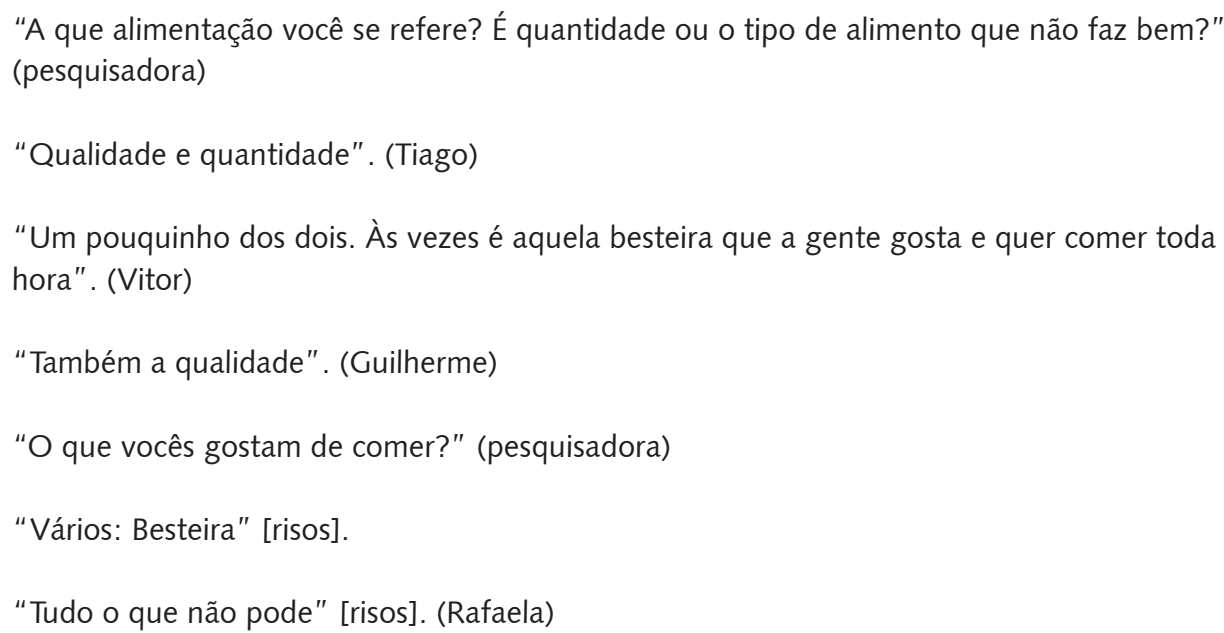

Ainda na linha da autocrítica aos hábitos alimentares, um integrante do grupo 3 disse, com tom de preocupação, que pensava em saúde quando comia gordura. "Eu como muita fritura" (Lucas).

A ideia de saúde foi também vinculada à autoimagem corporal e, secundariamente, à alimentação, por uma participante do grupo 2. Seu primeiro comentário ao tema sobre o momento em que pensava em saúde foi: "Quando me olho no espelho e vejo as gordurinhas. Tem que fazer dieta para emagrecer; é saúde" (Manuela). Embora fosse magra, a adolescente trouxe referências de um padrão estético difundido na atualidade.

Outro assunto vinculado à saúde por uma participante deste grupo foi a atividade sexual: "Até na relação sexual a gente tem que pensar em saúde, tomar remédio, usar camisinha... Tem que se prevenir, senão pega doença" (Isabele).

Em vários momentos, houve referências de integrantes do grupo a questões relacionadas à prática sexual (especialmente sobre gravidez e doenças sexualmente transmissíveis). A circulação de discursos preventivos de gravidez e doenças sexualmente transmissíveis mostrou-se intensa nos debates dos grupos. Alguns participantes manifestaram o esgotamento provocado pela repetição exaustiva de recomendações. No entanto, mesmo aqueles que expuseram a insatisfação com o volume de alertas sobre o assunto, consideraram importante a continuidade das campanhas e da divulgação ampliada.

A prática de atividades físicas também foi associada à saúde por integrantes de dois grupos, como reporta Luciano: "A gente pensa [em saúde] na hora do esporte também". Em outro grupo, foi feito um vínculo entre a incidência de doenças e a ausência de exercícios físicos. "[As pessoas que ficam doentes] são mais aquelas pessoas que não praticam nenhum exercício" (Henrique).

Contudo, os participantes foram irônicos ao abordarem a experiência própria. Embora incorporem a ideia de que esporte faz bem à saúde, não o praticam com regularidade. O diálogo aponta o acesso a informações de especialistas, mas, também, o distanciamento entre a prescrição e a conversão em prática.

\footnotetext{
“Eu não [pratico]". (Daniel)

"Eu pratico, todo dia. Acordar cedo". (André)

"Eu pratico todo dia. Acordo cedo, subo aquela passarela toda. Queima as calorias". (Carol)

"Ir para a escola". (Isabele)

"Eu pratico. Futebol". (Henrique)

"Ver televisão". (André)
} 


\author{
"Computador". (Caio) \\ "Exercícios para os dedos". (Paula)
}

Cuidados com a alimentação e prática de atividades físicas são temas destacados nos meios de comunicação como indicação médica de promoção da saúde ${ }^{(d)}$. A pesquisa apontou que tais prescrições reverberam entre os adolescentes, ou seja, têm acesso às recomendações mas as transgridem, o que contribui para atestar a não linearidade entre apropriação de informações e mudanças comportamentais.

\title{
Discursos circulantes sobre o cuidado
}

Um aspecto, observado nos três grupos, em relação ao tema "cuidado", foi a forte referência à mãe, de modo especial, ou a algum outro familiar (muitas vezes, uma outra figura feminina, como a avó), como a principal interlocução direcionada ao cuidado. Os alertas, segundo relataram vários participantes da pesquisa, são diários. Os relatos permitiram identificar três blocos temáticos desses alertas: os conjunturais, relacionados ao contexto em que vivem, associados a situações de violência; os vinculados à memória, às tradições familiares e ao saber popular; e aqueles comuns a outros contextos, no Brasil e em outras regiões, na atualidade.

Quadro 1. Alertas da família (especialmente da mãe)

\begin{tabular}{|c|c|}
\hline Blocos temáticos & Alertas mencionados nas discussões em grupo \\
\hline $\begin{array}{l}\text { Conjunturais } \\
\text { (ser morador da Maré) }\end{array}$ & $\begin{array}{l}\text { - Cuidado quando há tiroteio / "tiro na favela". } \\
\text { - Cuidado para não cair da laje. } \\
\text { - Cuidado com o "caveirão" [Veículo blindado usado pelo } \\
\text { policiamento especial nas operações na favela]. } \\
\text { - Cuidado com fogo [ao cozinhar]. } \\
\text { - Cuidado quando vê uma notícia [sobre operação policial ou tiroteio } \\
\text { na favela]. } \\
\text { - Cuidado com os cracudos [usuários de crack]. }\end{array}$ \\
\hline $\begin{array}{l}\text { Relacionados } \\
\text { a tradições culturais }\end{array}$ & $\begin{array}{l}\text {. Não andar descalça para o pé não crescer demais. } \\
\text {. Não sentar no chão quente para não pegar hemorroida. } \\
\text {. Não comer gelo. }\end{array}$ \\
\hline $\begin{array}{l}\text { Comuns a contextos mais } \\
\text { amplos no Brasil }\end{array}$ & $\begin{array}{l}\text { - Não andar descalço para não pegar resfriado. } \\
\text { - Não falar com estranhos. / Cuidado com as pessoas da rua } \\
\text { - Cuidado com o estuprador. } \\
\text { - Tomar cuidado para não ser atropelada. } \\
\text { - Cuidado com roubo ou assalto. } \\
\text { - Cuidado com a rua. } \\
\text { - Tomar cuidado com a internet [relacionamentos virtuais]. } \\
\text { - Não pegar carro [carona] com qualquer pessoa. } \\
\text { - Tomar cuidado para não deixar o gás ligado em casa. } \\
\text { - Quando vai a uma festa, cuidado com o copo. } \\
\text { - Levar casaco e guarda-chuva. } \\
\text { - Cuidado com quem vai se misturar. } \\
\text {. Cuidado com qualquer coisa. }\end{array}$ \\
\hline
\end{tabular}

(d) Dado obtido do monitoramento sobre câncer no jornal O Globo e na Revista Veja, durante o período de janeiro a junho de 2012, no âmbito do projeto "Os sentidos do câncer: um estudo sobre sofrimento, mídia e narrativas biográficas", coordenado por Kátia Lerner e com apoio do edital CNPq 43/2013 - Ciências Humanas, Sociais e Sociais Aplicadas. 
Dentre os alertas relacionados ao contexto em que vivem, observa-se a presença da mediação jornalística na fala: "Cuidado quando vê uma notícia [sobre operação policial ou tiroteio na favela]". O interesse pelo noticiário sobre os acontecimentos na Maré, especialmente aqueles relacionados à violência armada, aparece vinculado à temática do cuidado.

A última recomendação, "Cuidado com qualquer coisa", é reveladora da percepção sobre a amplitude dos perigos no contexto global contemporâneo, que guarda correspondência com o que Bauman ${ }^{19}$ define como a ubiquidade dos medos. A fala de uma adolescente toma esta direção: "Hoje em dia tudo é perigo, agora" (Carol).

De acordo com os adolescentes, algumas recomendações são seguidas por eles, mas nem todas. As falas abaixo mostram posicionamentos divergentes em relação às orientações recebidas. Foram retiradas de grupos distintos, não sendo apresentadas na sequência dos diálogos.

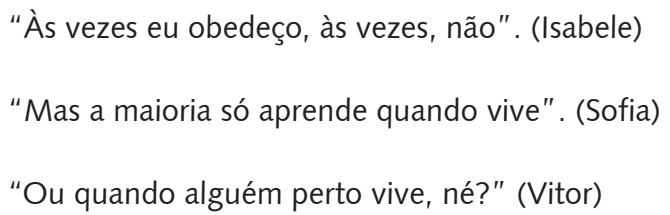

“Tipo assim, eu tenho mania de comer gelo. Aí minha avó fica: 'Cuidado, vai ficar doente, vai pegar uma pneumonia, vai parar no hospital'. Mas eu não quero saber não, como mesmo". (Paula)

"Eu gosto de andar de skate e tem muito lugar que minha mãe diz: "Olha, não vai andar lá!", e sempre que pego o skate, ando no lugar em que ela fala que não pode andar, porque são os lugares mais legais, por exemplo, onde passa muito carro". (Alex)

Vale observar, no entanto, que nenhum participante mencionou os alertas da mãe e de outros familiares em tom de reclamação ou, mesmo, de insatisfação. Ainda que alguns ironizassem as recomendações, tomadas como atitudes intrínsecas a qualquer movimentação deles, as citações foram carinhosas, como a justificar o gesto de proteção. Um exemplo foi a entonação suave usada por Luís (Grupo 3) em referência à mãe: "Qualquer coisa ela fica preocupada".

\section{Do estupro à internação hospitalar: os medos expressos}

Assim como houve diferença nas formas de vincular 'saúde' com 'cuidado' e 'cuidado' com 'saúde', os participantes da pesquisa relacionaram, de imediato, os termos 'perigo', 'cuidado' e 'risco', articulando-os em suas falas, mas não fizeram, a priori, o vínculo entre 'saúde', 'perigo' e 'risco'. A desconexão entre esses últimos, por associação livre, em contraste com a forte relação semântica feita entre perigo, cuidado e risco assinala o descolamento dos sentidos de saúde e risco para os participantes da pesquisa.

A discussão sobre risco foi ampliada, trazendo a percepção de sua imprevisibilidade, que se aproxima da ideia de fatalidade, e não de perigo como algo evitável, presente na perspectiva de prevenção para o controle do risco, na modernidade ${ }^{20,21}$. 
"Acho que tudo tem risco, gente. A gente pode tropeçar e cair lá embaixo. O prédio cair". (Guilherme)

"Tudo pode acontecer". (Luciano)

"Pode cair e quebrar a perna. Tudo é risco. Tudo é muito imprevisível". (Verônica)

O caráter ambivalente de 'perigo', que provoca medo e, ao mesmo tempo, atração, pôde ser observado nas frases:

\author{
"Perigo é o que não pode". (Nicole) \\ “Eu já passei por coisas arriscadas que podem..." (Guilherme) \\ "Adrenalina". (Verônica)
}

A expressão 'curiosidade' foi recorrente neste grupo, considerada por eles como uma característica de adolescentes e jovens. A palavra aparece como justificativa da exposição a situações 'perigosas ou arriscadas'.

\footnotetext{
“É o que a [nome da colega] reclamou aqui no meu ouvido [risos]. Ela falou que tem muitos riscos necessários para a nossa vida, para a curiosidade que a gente tem. Pelo menos eu sou muito curioso, gente". (Guilherme)

“Eu também. Tudo o que é perigoso a gente gosta, né?" (Flávia)

"Porque quebra a disciplina". (Aline)

"O que não pode, a gente quer fazer. Sair da rotina, do certo". (Guilherme)
}

As falas, observadas fora do contexto mais amplo das discussões, podem provocar a percepção da existência de um grau de adesão aos parâmetros definidos para comportamentos de adolescentes, largamente difundidos pelos meios de comunicação. Entretanto, participantes deste grupo questionaram, em outro momento, discursos sobre a adolescência que os caracterizam como sujeitos volúveis e problemáticos.

Os diálogos sobre os temas perigo e risco reportaram o sentimento de medo relacionado a situações contextuais, como a violência armada. O medo de ser baleado foi referido por alguns participantes da pesquisa.

Nas discussões em dois grupos, o medo do estupro foi mencionado repetidas vezes, como na fala de Carol: "Eu tenho medo de estupro, que fazem mais com a gente que é pequena." No grupo 3, o assunto suscitou relatos de episódios que envolveram pessoas próximas: uma participante citou o caso de abuso sexual de uma criança em sua família, por um parente próximo, sublinhando o impacto que isto gerou para todos, e para ela, especialmente; e um adolescente mencionou que uma amiga foi estuprada e morta por um amigo do pai dela.

Assaltos e roubos também foram citados em um dos grupos (2), gerando controvérsias sobre quem seria alvo desses atos. O diálogo permitiu divergências quanto ao risco de ser roubado ou assaltado, e argumentações com base em experiências pessoais. A referência aos idosos como pessoas que estariam mais vulneráveis a esse risco foi feita por integrantes do grupo 3. Em contrapartida, participantes dos grupos 1 e 2 mencionaram a pedofilia como uma ameaça direcionada a adolescentes também.

Além dos temores associados à violência, adolescentes do grupo 3 citaram medos relacionados à morte e ao sofrimento provocado por doenças. Novamente, a proximidade de experiências dolorosas 
foi vinculada ao sentimento, conforme o relato de um participante que perdeu um amigo vítima de câncer. Antes de citar o episódio e de nomear a doença, ele fez referência ao processo de sofrimento no ambiente hospitalar: "Só tenho medo de ficar internado" (Lucas). Quando questionado sobre o motivo, respondeu: "É, hospital público..." A discussão prosseguiu com a participação dos colegas:

\footnotetext{
"Eu tenho medo de morrer carbonizada". (Stefany)

"Ficar em hospital". (Sabrina)
}

"Eu não tenho medo de morrer, eu sei que um dia a morte vai chegar. Se estiver programado que vou morrer naquele dia, vou morrer naquele dia". (Stefany)

"Ah, não! Eu tenho medo de morrer". (Sabrina)

"Eu tenho medo de coisa tipo: vai sofrendo, sofre, sofre, sofre, e depois vai morrer". (Lucas)

"É, isso é muito ruim". (Sabrina)

"Mas vocês conhecem casos de pessoas jovens que passaram por isto?" (pesquisadora)

"Tem uma menina aqui na vila que morreu". (Stefany)

"Eu conheço. Meu amigo morreu de câncer". (Lucas)

"Teve que raspar a cabeça". (Stefany)

"Meu amigo tinha a minha idade. Ele tinha no pé. Depois cortou a perna e depois morreu, no ano passado". (Lucas)

Em resumo, os medos manifestados pelos adolescentes estão relacionados a dois tipos de situações: morte e adoecimento; e violência.

Quadro 2. Medos manifestados pelos participantes da pesquisa

\begin{tabular}{|l|l|}
\hline \multicolumn{1}{|c|}{ Medo da morte e do adoecimento } & \multicolumn{1}{c|}{ Medo da violência } \\
\hline . Medo de morrer. & . Medo de ser estuprada. \\
. Medo de morrer carbonizada. & . Medo de ser baleado. \\
- Medo de ficar internado & . Medo sde ser assaltado ou roubado. \\
- Medo de ter câncer. & . Medo de pedófilos. \\
\hline Medo de pegar HIV. & \\
\hline
\end{tabular}

O agrupamento dos medos em duas categorias buscou iluminar o forte impacto da violência nas manifestações dos participantes da pesquisa. Os relatos analisados na perspectiva da construção social de sentidos trazem à tona a convivência cotidiana com situações de violência na região onde vivem e, também, a violência simbólica, pulverizada em diferentes comunidades discursivas, em especial, nos meios de comunicação. 


\section{Considerações finais}

A extensa produção bibliográfica que associa 'risco' a 'adolescentes' revela o grau de interesse pela temática, particularmente na área da saúde, em grande medida, para embasar estudos que os posicionam no foco das atenções da promoção de saúde. Esta constatação não se propõe a desqualificar as iniciativas de prevenção de riscos à saúde do adolescente. Tampouco desconsidera as reflexões surgidas a partir delas. Ao buscar compreender como esses indivíduos se apropriam das informações circulantes em suas redes discursivas sobre saúde, cuidado e risco, a pesquisa realizada propõe-se a contribuir para a reflexão sobre as políticas de promoção de saúde dirigidas a esse grupo populacional.

A partir das atividades realizadas, foi possível observar a demanda 'introjetada' de discursos da cultura do risco, que reforçam a necessidade permanente de cuidar de si, por meio de mecanismos de autocontrole, manifestados, por exemplo: na autocrítica quanto ao consumo de alimentos que não seriam saudáveis (comer besteira), na prática de atividade física ou no uso de preservativos nas relações sexuais.

Tais discursos concorrem com os argumentos de prevenção ao risco inscritos nas próprias construções que enquadram os adolescentes como grupos de risco. Ao justificarem algumas atitudes de submissão a riscos pela 'curiosidade do adolescente', participantes da pesquisa apontaram a contradição contida nos alertas ao cuidado de si.

Esta correlação, feita de forma recorrente por vozes especialistas acionadas nos canais de comunicação, não apenas reduz as motivações de submissão a riscos à dimensão biológica, pelo crivo homogeneizador da faixa etária, como aponta um obstáculo intransponível para as estratégias de proteção desses indivíduos. Afinal, se a curiosidade é considerada uma característica constitutiva da adolescência, estaria justificada a maior submissão a riscos pelos indivíduos assim caracterizados, e pouco ou nada restaria a fazer por parte dos formuladores de políticas públicas de promoção de saúde e profissionais do campo.

No que se refere às redes de sentidos dos participantes da investigação, o estudo apontou a forte interlocução com a família, especialmente com a mãe, e a percepção de que esta mediação traz, também, leituras e interpretações desses outros sujeitos a partir do acesso que fazem dos meios, atravessado, igualmente, pelo processo de midiatização, além dos acionamentos das tradições culturais desses atores sociais.

Outros mediadores destacados nos diálogos nos grupos foram: os profissionais de saúde, em particular, os médicos que atuam na atenção básica, nos postos de saúde da Maré; e os meios de comunicação, em especial, o suporte televisivo e a internet.

Embora as práticas dos adolescentes relativas aos cuidados com a saúde não tenham sido objeto de estudo, e sim os sentidos atribuídos por eles aos temas, a investigação trouxe elementos significativos para referendar a fragilidade da perspectiva que atribui o cuidado de si ao conhecimento do risco. Ainda que os indivíduos potencialmente expostos não tenham essa experiência, o acesso à informação sobre um determinado perigo é insuficiente para a tomada de atitude preventiva. Conforme sustenta Beck ${ }^{21}$, a capacidade de perceber riscos e convertê-los em referenciais para pensar e agir depende de as relações causais estabelecidas entre circunstâncias e projeções menos especulativas tornarem-se críveis e imunes a prováveis objeções.

Os limites de estudos centrados no conhecimento e nas atitudes dos indivíduos foram ressaltados por pesquisadores como Paiva ${ }^{22}$, em análises sobre a prevenção ao HIV. Orientada pela perspectiva dialógica freireana, a autora aponta caminhos de interlocução para a composição de cenários culturais, por meio de espaços de interação e redes sociais.

Adotando premissa semelhante, este artigo privilegiou a compreensão dos sentidos de saúde, cuidado e risco pelos participantes da pesquisa. Ao se analisarem os lugares de interlocução desses jovens, ou seja, o lugar social a partir do qual se comunicavam, associando-os aos diferentes contextos em que estavam inseridos ${ }^{23}$, acredita-se poder contribuir para a construção de um conhecimento que possibilite a formulação de políticas mais próximas de sua realidade. Tal aposta, materializada por uma estratégia metodológica que inclua os sujeitos de pesquisa como parte ativa na investigação, reforça a demanda por investimento no processo de pesquisa. 


\section{Colaboradores}

Marcia Rodrigues Lisboa responsabilizou-se pela concepção do artigo, pela coleta e análise de dados e pela redação do texto. Kátia Lerner orientou a pesquisa, trabalhou na revisão crítica do manuscrito e auxiliou na normalização da versão final.

\section{Referências}

1. Lisboa MR. Cuidado, ser adolescente é arriscado: formas de apropriação de produtos jornalísticos sobre cuidado e risco à saúde por adolescentes da Maré [tese]. Rio de Janeiro (RJ): Fundação Oswaldo Cruz; 2014.

2. Ayres JRCM. Sujeito, intersubjetividade e práticas de saúde. Cien Saude Colet. 2001; 6(1):63-72.

3. Freire Filho J. Retratos midiáticos da nova geração e a regulação do prazer juvenil. In: Borelli S, Freire Filho J, organizadores. Culturas juvenis no século XXI. São Paulo: Educ; 2008. p. 33-57.

4. Rocha $E$, Pereira $C$. Juventude e consumo: um estudo sobre a comunicação na cultura contemporânea. Rio de Janeiro: Mauad X; 2009.

5. Castiel LD, Sanz-Valero J, Vasconcellos-Silva PR. Das loucuras da razão ao sexo dos anjos. Rio de Janeiro: Fiocruz; 2011.

6. Boltanski L, Chiapello E. O novo espírito do capitalismo. São Paulo: WMF/Martins Fontes; 2009.

7. Ehrenberg A. O culto da performance: da aventura empreendedora à depressão nervosa. Aparecida: Ideias e Letras; 2010.

8. Sodré M. Antropológica do espelho: uma teoria da comunicação linear e em rede. Petrópolis: Vozes; 2002.

9. Sodré M. A ciência do comum: notas para o método comunicacional. Petrópolis: Vozes; 2014.

10. Novaes R. Os jovens de hoje: contextos, diferenças e trajetórias. In: Almeida, IM, Eugenio F, organizadores. Culturas jovens: novos mapas do afeto. Rio de Janeiro: Zahar; 2006. p. 105-20.

11. Weller W. Grupos de discussão na pesquisa com adolescentes e jovens: aportes teórico-metodológicos e análise de uma experiência com o método. Educ Pesqui. 2006; 32(2):241-60.

12. Foucault M. Microfísica do poder. 8a ed. Rio de Janeiro: Graal; 1989. p. 79-112.

13. Castiel LD, Guilam MC, Ferreira MS. Correndo o risco: uma introdução aos riscos em saúde. Rio de Janeiro: Fiocruz; 2010 (Temas em saúde).

14. Paim JS, Almeida Filho N. Saúde coletiva: uma "nova saúde pública" ou campo aberto a novos paradigmas? [Internet]. 1998 [citado 27 Jan 2012]. Disponível em: http://www. scielo.br/scielo.php?script $=$ sci_arttext\&pid $=$ S0034-89101998000400001\&lng $=$ en \&nrm $=$ iso.

15. World Health Organization. Basic documents. 47a ed. Genebra: WHO; 2009.

16. Canguilhem G. O normal e o patológico. 6a ed. Rio de Janeiro: Forense Universitária; 2010.

17. Almeida Filho N. O que é saúde? Rio de Janeiro: Fiocruz; 2011.

18. Foucault M. História da sexualidade III: o cuidado de si. Rio de Janeiro: Graal; 1985.

19. Bauman Z. Medo líquido. Rio de Janeiro: J. Zahar; 2008. 
20. Giddens A. Modernidade e identidade. Rio de Janeiro: Zahar; 2001. p. 104-34.

21. Beck U. Sociedade de risco: rumo a uma outra modernidade. São Paulo: Editora 34; 2010.

22. Paiva V. Analisando cenas e sexualidades: a promoção da saúde na perspectiva dos direitos humanos. In: Cárceres C, Careaga G, Frasca T, Pecheny M, organizadores. Sexualidad, estigma y derechos humanos. Desafíos para el acceso a la salud en América Latina. Lima: FASPA/UPCH; 2006.

23. Araújo I, Cardoso J. Comunicação e saúde. Rio de Janeiro: Fiocruz; 2007.

Lisboa MR, Lerner K. Sentidos de salud, cuidado y riesgo para adolescentes residentes en la Favela da Maré, en Río de Janeiro, Brasil. Interface (Botucatu). 2017; 21(63):893-906.

Se trata de un estudio cualitativo sobre los sentidos atribuidos a los términos salud, cuidado y riesgo por parte de adolescentes brasileños residentes en el conjunto de favelas da Maré, en el municipio de Río de Janeiro. El análisis usa como referencias reflexiones sobre la perspectiva epidemiológica de encuadramiento de los individuos de ese rango de edad en la categoría grupo de riesgo y el proceso de mediatización social que potencializa la circulación de informaciones sobre la temática. El principal instrumento de colecta de datos fueron discusiones en grupo con adolescentes entre 14 y 16 años. Las dinámicas permitieron observar la presencia de discursos concurrentes de la cultura del riesgo, de tradiciones familiares y del contexto de violencia en el cotidiano de los participantes. Se destacan las mediaciones de las madres, de los médicos que actúan en la atención básica y de los medios de comunicación en la construcción social de esos sentidos.

Palabras clave: Adolescencia. Comunicación. Salud. Cuidado. Riesgo.

Submetido em 19/11/15. Aprovado em 08/10/16. 